\title{
PENAFSIRAN KISAH LUQMAN DALAM AL-QUR'AN: Relevansinya dengan Pendidikan Keimanan dalam Keluarga
}

\author{
Rusydi AM \\ UIN Imam Bonjol Padang \\ E-mail: rusydi.am@yahoo.com
}

\begin{abstract}
Abstrak
Kisah atau sejarah adalah salah satu bagian dari kandungan yang terdapat dalam alQur'an. Pengungkapan berbagai bentuk kisah itu bukan tanpa makna dan nilai, karenaAllah tegaskan bahwa pada kisah-kisah itu terdapat ibrah (pelajaran) yang dapat ditangkap oleh orang-orang yang punya nyali tinggi yang al-Qur'an menyebutnya dengan istilah ulul albab.Salah suatu kisah itu adalah tentang Luqmanul Hakim terdapat dalam surat ke31, yaitu Surat Luqman. Luqman banyak memberikan berbagai petunjuk kepada anaknya, hal itu dapat dilihat pula dalam berbagai perspektif; akidah, ibadah, dan akhlak. Pengungkapan kisah Luqman ini dalam al-Qur'an dapat dijadikan acuan dan pedoman dasar bagi keluarga Muslim,-terutamauntuk dikembangkan dan diaplikasikan bagi keluarga masing-masing yang muaranya untuk menampakkan dan memainkan peran keluarga dalam pendidikan generasi muda, terutama dalam pembentukan keluarga yang Islami, tentu saja dalam perspektif dunia pendidikan. Hal itu, secara spesifik dapat dikategorikan tentang materi pendidikan, metode pendidikan, bahkan seni mendidik.
\end{abstract}

Kata kunci : Kisah, ibrah, ulul al-bab, tauhid, pendidikan, keluarga.

\section{Pendahuluan}

Keimanan merupakan keyakinan yang harus dimiliki oleh umat yang beragama, terutama Islam.Sebagai penganut Islam, keimanan menjadi penentu dan identitas seseorang dalam meyakini Allah sebagai Tuhannya.Dalam perkembangannya, keimanan mampu menjadi pengontrol dalam menjalani kehidupan seseorang.Begitu juga bahwa keimanan mampu untuk memberikan motivasi guna melaksanakan berbagai perintah dan meninggalkan laranganlarangannya. Sehingga konsep dosa dan pahala tertanam dalam hidupnya.

Kewajiban bagi setiap muslimin dan muslimat untuk mengetahui tiga hal pokok dalam agama, yaitu mengetahui Rabbnya, mengetahui agamanya dan mengetahui Nabinya.Pengetahuan terhadap ketiga hal pokok tersebut bukan hanya sekedar pengetahuan saja, akan tapi harus dibenarkan dengan hati, diucapkan dengan lisan dan diamalkan dengan perbuatan dalam kehidupan sehari-hari, dan itulah yang dimaksud dengan iman. Dan keimanan yang ada pada seseorang harus senantiasa ada dan berkembang serta harus benarbenar dijaga kemurniannya. Tidaklah dibenarkan jika keimanan itu dicampuradukkan dengan berbagai kegiatan yang bertabur khurafat dan takhayul. Dan jika hal itu terjadi bukan lagi keimanan namanya melainkan kemusyrikan.

Saat ini fenomena kemusyrikan sudah banyak yang dibingkai dengan 
bingkai agama, sehingga ada sebagian orang yang mempunyai anggapan keliru di saat selesai melakukan perbuatan syirik yang dibingkai dengan bingkai agama itu bahwa dia telah melaksanakan ajaran agama, padahal apa yang dia lakukan adalah perbuatan yang penuh dengan kesyirikan. Syirik adalah dosa besar yang tidak akan diampuni Allah manakala orang yang bersangkutan tidak mohon ampunanNya sebelum dia meninggal dunia.

Selain fenomena kemusyrikan, yang harus diwaspadai agar keimanan kita dan peserta didik tetap ada dan terjaga kemurniannya adalah "Riddah" atau keluar dari ajaran Islam. Fenomena yang kedua ini tidak kalah dahsyatnya berkembang dalam kehidupan sehari-hari dan kebanyakan diantara kita sering tidak sadar bahwa apa yang diucapkan, yang diperbuat, termasuk yang digerakan (dikeretegkeun : sunda) dalam hati bisa menyebabkan keluarnya kita dari Agama Islam (murtad).Sesuai dengan latar belakang di atas maka perlu dirumuskan tentang pentingnya pendidikan keimanan sebagai upaya sistematis dalam pendidikan agar keimanan kita tetap terjaga kemurniannya dan terhindar dari berbagai hal yang bisa merusak keimanan kita. Iman menjadi dalam kehidupan manusia dalam menjalan hidup dan kehidupannya. Luqman telah mencontoh langkah antisipatif dan kuratif kepada anak-anaknya agar mereka terhindar kemusyrikan tersebut dan konsekuen dengan tauhid kepada Allah.

\section{Pendidikan Keimanan dalam Keluarga}

Istilah pendidikan berasal dari kata "didik" yang diberi awalan "pe" dan akhiran "kan", mengandung arti "perbuatan" (hal, cara, dan sebagainya). Istilah pendidikan ini semula berasal dari Bahasa Yunani yaitu "Paedagogie", yang berarti bimbingan yang diberikan kepada anak. ${ }^{1}$ Dalam Kamus Besar Bahasa Indonesia pendidikan ialah "Proses pengubahan sikap dan tata laku seseorang atau kelompok orang dalam usaha mendewasakan manusia melalui upaya pengajaran."2

Dalam pandangan agama Islam, keluarga memiliki nilai dan peran yang demikian strategis dan tinggi. Oleh karena itu, Islam memberikan perhatian yang cukup besar terhadap kehidupan keluarga dengan meletakkan dasardasar yang arif guna memelihara kehidupan yang harmonis dalam keluarga. Hal itu, karena tidak dapat dibantah bahwa keluara adalah dasar pertama dan utama untuk mewujudkan masyarakat, bahkan bangsa yang damai dan sejahtera, atau negeri yang diistilahkan al-Quran dengan "baldatun thayyibatun wa rabbun ghafur". Sejalan dengan hal itu Satiadarma menulis:

Tak disangkal bahwa keluarga merupakan tempat pertama bagi anak untuk belajar interaksi sosial. Melalui keluargalah anak belajar merespon terhadap masyarakat dan beradaptasi di tengah kehidupan masyarakat dan yang lebih luas kelak. Melalui proses inilah, seorang anak secara bertahap belajar mengembangkan potensi diri, dan kemampuannalar serta

\footnotetext{
${ }^{1}$ Ramayulis, Ilmu Pendidikan Islam, (Jakarta: Kalam Mulia, 2002), h. 13

2 Tim Penyusun Kamus Pusat Pembinaan dan Pengembangan Bahasa Departemen Pendidikan dan Kebudayaan, Kamus Besar Bahasa Indonesia, (Jakarta: Balai Pustaka, 2007), Cet. III, h. 263
} 
imajinasinya dan tahapan perkembangan berikutnya. $^{3}$

Ahmad Tafsir menjelaskan bahwa pendidikan adalah usaha meningkatkan diri dalam segala aspeknya. Definisi ini mencakup kegiatan pendidikan yang melibatkan guru maupun yang tidak melibatkan guru (pendidik); mencakup pendidikan formal, maupun nonformal serta informal. Segi yang dibina oleh pendidikan dalam definisi ini adalah seluruh aspek kepribadian". ${ }^{4}$ Pengertian pendidikan menurut Armai Arief yaitu pendidikan merupakan usaha yang dilakukan oleh orang dewasa kepada anak-anak dalam rangka untuk membimbing perkembangan rohani dan jasmaninya menuju ke arah kedewasaan, sehingga dengan adanya bimbingan ini dapat menjadikan anak menjadi manusia yang berguna baik untuk dirinya sendiri ataupun untuk hidup dalam masyarakat. ${ }^{5}$

\section{Kisah Luqman dalam Al Qur'an}

Di antara ayat-ayat AlQur'anyang menjelaskan kisah Luqman terdapat dalam Surat Luqman Ayat:13-15berikut ini :

وَإِذْ قَالَ لُقْمَانُ لِابنِْهِ وَهُوَ يَعِظُهُ يَا بُنَيَّ لَا تُشْرِكْ

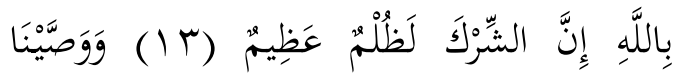

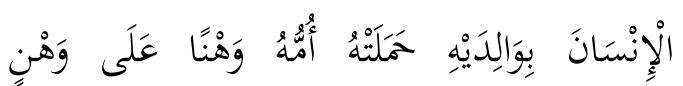

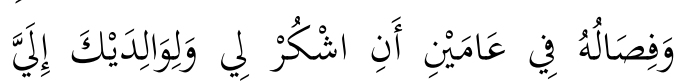

${ }^{3}$ Monti P. Satiadarma, Persepsi Orang Tua Membentuk Perilaku Anak: Dampak Pigmalion dalam Keluarga, ( Jakarta: Pustaka Populer Obor, 2001), h. 121.

4 Ahmad Tafsir, Metodologi Pengajaran Agama Islam, (Bandung: PT. Remaja Rosdakarya, 2007), Cet. IX, h. 6

${ }^{5}$ Armai Arief, Refolmulasi Pendidikan Islam, (Jakarta: Crsd Press, 2005), Cet. I, h. 17
الْمَصِيرُ (ع ا ) وَإِنْ جَاهَدَاكَ عَلَكلى أَنْ تُشْرِكَ بِي

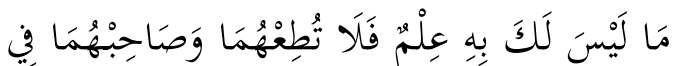

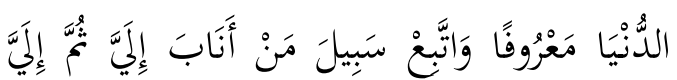

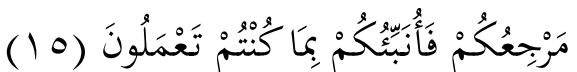
Artinya :13. Dan (Ingatlah) ketika Luqman Berkata kepada anaknya, di waktu ia memberi pelajaran kepadanya: "Hai anakku, janganlah kamu mempersekutukan Allah, Sesungguhnya mempersekutukan (Allah) adalah benar-benar kezaliman yang besar".14. Dan kami perintahkan kepada manusia (berbuat baik) kepada dua orang ibu- bapanya; ibunya Telah mengandungnya dalam keadaan lemah yang bertambah- tambah, dan menyapihnya dalam dua tahun[1180]. bersyukurlah kepadaku dan kepada dua orang ibu bapakmu, Hanya kepada-Kulah kembalimu.15. Dan jika keduanya memaksamu untuk mempersekutukan dengan Aku sesuatu yang tidak ada pengetahuanmu tentang itu, Maka janganlah kamu mengikuti keduanya, dan pergaulilah keduanya di dunia dengan baik, dan ikutilah jalan orang yang kembali kepada-Ku, Kemudian Hanya kepada-Kulah kembalimu, Maka Kuberitakan kepadamu apa yang telah kamu kerjakan.

Ibnu Katsir dalam tafsirnya menjelaskan bahwa Allah Swt. menceritakan tentang nasehat Luqman kepada anaknya. Luqman adalah anak Anqa ibnu Sadun, dan nama anaknya ialah Saran, menurut suatu pendapat yang diriwayatkan oleh Imam Baihaqi.Allah Swt. menyebutkan kisah Luqman dengan baik, bahwa Dia telah menganugerahinya hikmah; dan Luqman memberikan nasehat kepada 
anaknya yang merupakan buah hatinya, maka wajarlah bila ia memberikan kepada orang yang paling dikasihinya sesuatu yang paling utama dari pengetahuannya. Karena itulah hal pertama yang dia pesankan kepada anaknya adalah agar dia (anaknya) menyembah Allah semata, tidak mempersekutukan-Nya dengan sesuatu pun. Kemudian Luqman memperingatkan anaknya, bahwa

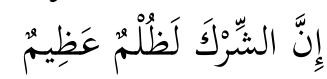

Artinya: mempersekutukan (Allah) adalah benar-benar kezaliman yang besar". (Luqman: (31): 13). ${ }^{6}$

Dalam ayat ini Allah tegaskan bahwa perbuatan mempersekutukan Allah (syirik) itu adalah perbuatan aniaya ( kezaliman) yang paling besar. Bahkan, menurut Said Quthb, bahwa apa yang dilakukan oleh Luqman adalah cerminan betapa besar tanggung jawabnya selaku orang tua terhadap anaknya. Bahkan, dalam ayat ini terdapat dua buah ta'kid (penguatan), yaitu dengan mengemukakan larangan dan menjelaskan sebabnya, dan kali kedua dengan adanya "inna" dan "lam" yang menunjukkan takkid. ${ }^{7}$

Hal ini senada dengan hadis riwayat Bukhari :

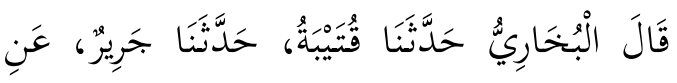

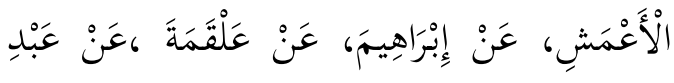

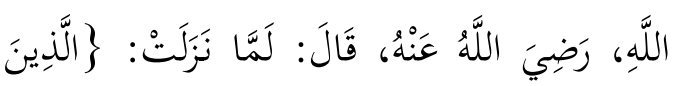

${ }^{6}$ Ismail Ibn Katsir al-Qursyi alDimasyqi, Tafsir al-Qur'an al-'Azhim ( Kairo: Maktabah al-Dakwah al-Islamiyah Syabab AlAzhar, tt), Juz. III, h. 443

${ }^{7}$ Said Quthb, Fi Zhilal Al-Qur'an, ( Kairo: Dar al-Syuruq, 1981), Jilid 5, h. 2788

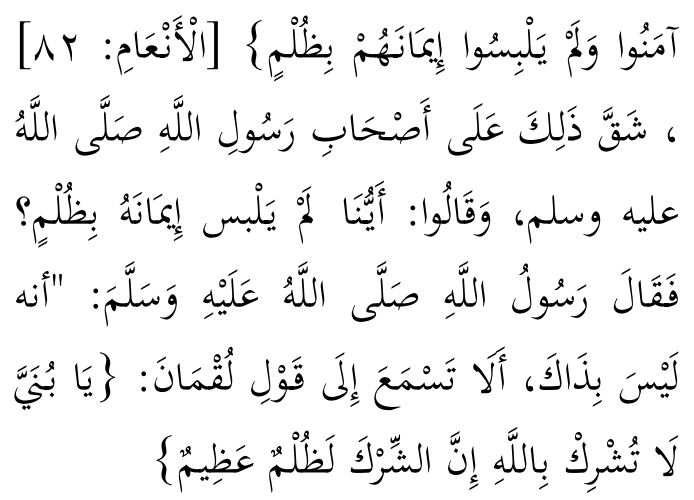

Imam Bukhari mengatakan, telah menceritakan kepada kami Qutaibah, telah menceritakan kepada kami Jarir, dari Al-A'masy, dari Ibrahim, dari Alqamah, dari Abdullah yang menceritakan bahwa ketika diturunkan firman-Nya: Orang-orang yang beriman dan tidak mencampuradukkan iman mereka dengan kezaliman (syirik). (Al-An'am: 82) Hal itu terasa berat bagi para sahabat Nabi Saw. Karenanya mereka berkata, "Siapakah di antara kita yang tidak mencampuri imannya dengan perbuatan zalim (dosa)." Maka Rasulullah Saw. bersabda, "Bukan demikian yang dimaksud dengan zalim. Tidakkah kamu mendengar ucapan Luqman: 'Hai anakku, janganlah kamu mempersekutukan Allah, sesungguhnya mempersekutukan (Allah) adalah benar-benar kezaliman yang besar.' (Luqman: 13).

Imam Muslim meriwayatkannya melalui hadis Al-A'masy dengan sanad yang sama.

Kemudian sesudah menasihati anaknya agar menyembah Allah semata. Luqman menasehati pula anaknya agar berbakti kepada dua orang ibu dan bapak. Perihalnya sama dengan apa yang disebutkan oleh firman-Nya dalam ayat yang lain, yaitu: 


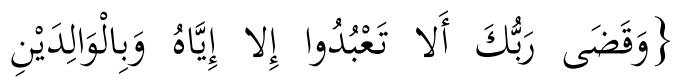

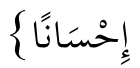

Dan Tuhanmu telah memerintahkan supaya kamu jangan menyembah selain Dia dan hendaklah kamu berbuat baik pada ibu bapakmu dengan sebaik-baiknya. (Al-Isra: 23).

Di dalam Al-Qur'an sering sekali disebutkan secara bergandengan antara perintah menyembah Allah semata dan berbakti kepada kedua orang tua. Dan dalam surat ini disebutkan oleh firmanNya:

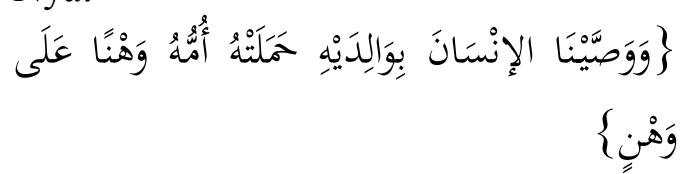

Dan Kami perintahkan kepada manusia (berbuat baik) kepada dua orang ibu bapaknya; ibunya telah mengandungnya dalam keadaan lemah yang bertambah-tambah. (Luqman: 14)

Mujahid mengatakan, yang dimaksud dengan al-wahn ialah penderitaan mengandung anak. Menurut Qatadah, maksudnya ialah kepayahan yang berlebih-lebihan. Sedangkan menurut Ata Al-Khurrasani ialah lemah yang bertambah-tambah. Firman Allah Swt.:

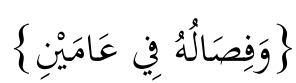

dan menyapihnya dalam dua tahun. (Luqman: 14)

Yakni menyusuinya selama dua tahun, seperti yang disebutkan dalam ayat lain melalui firman-Nya:

$$
\begin{aligned}
& \text { \}وَالْوَالِدَاتُ يُرْضِعْنَ أَوْلادَهُنَّ حَوْلَيْنِ كَامِلَيْنِ لِمَنْ }
\end{aligned}
$$

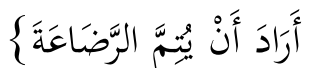

Para ibu hendaklah menyusukan anak-anaknya selama dua tahun penuh, yaitu bagi yang ingin menyempurnakan penyusuan. Baqarah: 233).

Berangkat dari pengertian ayat ini Ibnu Abbas dan para imam lainnya menyimpulkan bahwa masa penyusuan yang paling minim ialah enam bulan, karena dalam ayat lain Allah Swt. berfirman:

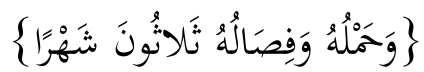

Mengandungnya sampai menyapihnya adalah tiga puluh bulan. (Al-Ahqaf: 15)

Dan sesungguhnya Allah Swt. menyebutkan jerih payah ibu dan penderitaannya dalam mendidik dan mengasuh anaknya, yang karenanya ia selalu berjaga sepanjang siang dan malamnya. Hal itu tiada lain untuk mengingatkan anak akan kebaikan ibunya terhadap dia, sebagaimana yang disebutkan dalam ayat lain melalui firman-Nya:

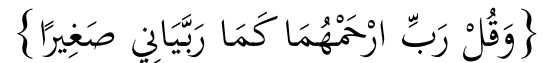

$$
\begin{aligned}
& \text { Dan ucapkanlah, "Wahai }
\end{aligned}
$$

Tuhanku, kasihilah mereka keduanya, sebagaimana mereka berdua telah mendidik aku waktu kecil." (Al-Isra: 24).

Karena itulah dalam surat ini disebutkan oleh firman-Nya:

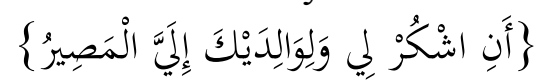

Bersyukurlah kepada-Ku dan kepada dua orang ibu bapakmu, hanya kepada-Kulah kembalimu. (Luqman: 14)

Maksud ayat ini adalah bahwasesungguhnya Aku akan memberikan pembalasan dengan pahala yang berlimpah bila kamu bersyukur.Ibnu Abu Hatim mengatakan, telah menceritakan kepada kami Abu Zar'ah, telah menceritakan kepada kami Abdullah ibnu Abu Syaibah dan Mahmud ibnu 
Gailan. Keduanya mengatakan, telah menceritakan kepada kami Ubaidillah, telah menceritakan kepada kami Israil, dari Abu Ishaq, dari Sa'id ibnu Wahb yang menceritakan bahwa Mu'az ibnu Jabal datang kepada kami sebagai utusan Nabi Saw. Lalu ia berdiri dan memuji kepada Allah, selanjutnya ia mengatakan: Sesungguhnya aku adalah utusan Rasulullah Saw. kepada kalian (untuk menyampaikan), "Hendaklah kalian menyembah Allah dan janganlah mempersekutukan-Nya dengan sesuatu pun. Hendaklah kalian taat kepadaku, aku tidak akan henti-hentinya menganjurkan kalian berbuat kebaikan. Dan sesungguhnya kembali (kita) hanya kepada Allah, lalu adakalanya ke surga atau ke neraka sebagai tempat tinggal yang tidak akan beranjak lagi darinya, lagi kekal tiada kematian lagi.Firman Allah Swt.:

$$
\begin{aligned}
& \text { جوَإِنْ جَاهَدَاكَ عَلَى أَنْ تُشْرِكَ بِي مَا لَيْسَ لَكَ }
\end{aligned}
$$

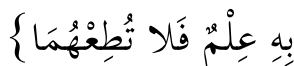

Dan jika keduanya memaksamu untuk mempersekutukan dengan Aku sesuatu yang tidak ada pengetahuanmu tentang itu, maka janganlah kamu mengikuti keduanya. (Luqman: 15)

Jika keduanya (ibu - bapak)mu menginginkan dirimu dengan sangat agar kamu mengikuti agama keduanya (selain Islam), janganlah kamu mau menerima ajakannya, tetapi janganlah sikapmu yang menentang dalam hal tersebut menghambatmu untuk berbuat baik kepada kedua orang tuamu selama di dunia.

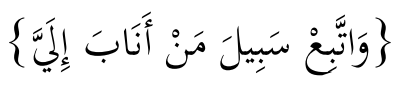

Dan ikutilah jalan orang yang kembali kepada-Ku.(Luqman: 15) beriman.

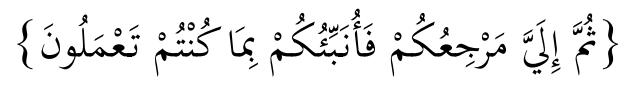

Kemudian hanya kepada-Kulah kembalimu, maka Kuberitakan kepadamu apa yang telah kamu kerjakan. (Luqman: 15)

Imam Tabrani mengatakan di dalam Kitab al-'Asyarah-nya, telah menceritakan kepada kami Abu Abdur Rahman Abdullah ibnu Ahmad ibnu Hambal, telah menceritakan kepada kami Ahmad ibnu Ayyub ibnu Rasyid, telah menceritakan kepada kami Maslamah ibnu Alqamah, dari Daud ibnu Abu Hindun, bahwa Sa'd ibnu Malik pernah mengatakan bahwa ayat berikut diturunkan berkenaan dengannya, yaitu firman-Nya: Dan jika keduanya memaksamu untuk mempersekutukan dengan Aku sesuatu yang tidak ada pengetahuanmu tentang itu, maka janganlah kamu mengikuti keduanya. (Luqman: 15), hingga akhir ayat. Bahwa ia adalah seorang yang berbakti kepada ibunya. Ketika ia masuk Islam, ibunya berkata kepadanya, "Hai Sa'd, mengapa engkau berubah pendirian? Kamu harus tinggalkan agama barumu itu (Islam) atau aku tidak akan makan dan minum hingga mati, maka kamu akan dicela karena apa yang telah kulakukan itu, dan orang-orang akan menyerumu dengan panggilan, 'Hai pembunuh ibunya!'." Maka aku menjawab, "Jangan engkau lakukan itu, Ibu, karena sesungguhnya aku tidak bakal meninggalkan agamaku karena sesuatu." Maka ibuku tinggal selama sehari semalam tanpa mau makan, dan pada pagi harinya ia kelihatan lemas. Lalu ibuku tinggal sehari semalam lagi tanpa makan, kemudian pada pagi harinya kelihatan bertambah lemas lagi. Dan ibuku tinggal sehari semalam lagi tanpa makan, lalu pada pagi 
harinya ia kelihatan sangat lemah. Setelah kulihat keadaan demikian, maka aku berkata, "Hai ibu, perlu engkau ketahui, demi Allah, seandainya engkau mempunyai seratus jiwa, lalu satu persatu keluar dari tubuhmu, niscaya aku tidak akan meninggalkan agamaku karena sesuatu. Dan jika Allah SWT dalam QS. Luqman [31]:13 tersebut merupakan 'athaf terhadap makna ayat yang disebutkan sebelumnya. Allah SWT memberikan Lukman hikmah ketika dia dijadikan orang yang bersyukur atas dirinya dan ketika dia dijadikan orang yang memberikan nasehat terhadap orang lain. ${ }^{8}$ Demikian ini adalah alasan tingginya derajat seseorang yaitu ketika dia secara pribadi sempurna dan sekaligus menyempurnakan orang lain. Firman Allah "anisykur"(hendaklah engkau bersyukur) dalam QS. Lukman (31):12 adalah isyarat yang menunjukkan kepada adanya penyempurnaan untuk orang lain. Ayat ini mengandung pesan yang halus bahwa Allah menyebutkan kisah Luqman dan memuji usahanya, Allah memberikan petunjuk kepada sianak agar dia belajar dari ayahnya tentang fadhilah nabi, yang memberi petunjuk kepada kerabat dekat dan orang lain. Memberi petunjuk kepada anak adalah sesuatu yang lazim dan semestinya, sedangkan menanggung beban dengan memberi pelajaran kepada orang lain bukanlah sesuatu yang biasa.

Dengan demikian, menurut penulis bahwa ayat diatas jelas mengisyaratkan kepada kaum muslimin bahwa pendidikan keimanan merupakan pendidikan yang pertama

\footnotetext{
${ }^{8}$ Ismail Ibn Katsir al-Qursyi al-

${ }^{8}$ Ismail Ibn Katsi
Dimasyqi, Op.Cit., h. 445
}

dan yang utama lagi mendasar yang harus diberikan orang tua kepada anaknya. Hal ini dapat dipahami dari nasehat Luqman kepada anaknya, dimana nasehat yang pertama adalah larangan mensekutukan Allah dengan yang lain, karena menyekutukan Allah merupakan perbuatan zhalim yang sangat besar. Ini dapat dipahami bahwa menanamkan keimanan yang benar kepada anak merupakan perintah Allah yang harus dilakukan oleh setiap orang tua muslim, karena kalau tidak akan berdampak kepada aspek lain dari kehidupan anak, seperti aspek akhlak anak. Disamping itu, ayat ini juga mengisyaratkan bahwa orang tua selaku pendidik keimanan bagi anak, hendaklah terlebih dahulu memiliki keimanan yang sempurna kepada Allah, karena hal ini akan berpengaruh besar kepada keberhasilannya dalam melakukan proses pendidikan keimanan tersebut hal ini sebagaimana tampak pada diri Luqman.

Ayat-ayat diatas menggambarkan tentang metode atau cara yang digunakan Al-Qur'andalam melakukan pendidikan keimanan. Adapun caranya adalah dengan menggunakan dialog, yaitu antara Luqman dengan anaknya dan juga Nabi Ibrahim dengan bapak dan kaumnya yang musyrik. Berbagai pertanyaan diajukan Ibrahim kepada bapak dan pengikutnya yang musyrik untuk melemahkan keyakinan yang mereka pegang selama ini.

\section{Implikasi Keimanan dalam Pendidikan Islam}

Uraian mengenai keimnan kepada Allah SWT dan pendidikan keimanan sebagaimana dapat dipahami dari kandungan ayat-ayat diatas memiliki hubungan yang erat dengan 
pendidikan Islam. Hal ini dapat dijelaskan sebagai berikut:

1. Keimanan kepada Allah SWT dengan segala uraian yang berkaitan dengannya, selain menjadi materi utama pendidikan Islam, juga dapat menjadi dasar bagi perumusan tujuan pendidikan, dasar penyususnan kurikulum dan aspek-aspek pendidikan lainnya. Dikalangan ahli pendidikan disepakati bahwa mata pelajaran tentang keimanan termasuk mata pelajaran pokok dalam pendidikan Islam.misalnya, dalam kurikulum pendidikan Islam dijumpai mata kuliah atau mata pelajaran akidah Islam, dengan berbagai namanya, seperti, ilmu Aqaid, ilmu Ushuluddin, ilmu Tauhid. Mata pelajaran ini harus diberikan terlebih dahulu dengan alasan bahwa iman merupakan sesuatu yang urgen dalam kehidupan manusiadan sangat menentukan hasil dari segala amal perbuatannya. Selanjutnya tujuan pendidikan Islam juga harus berkaitan dengan keimanan dan ketaqwaan kepada Allah SWT. Para ahli pendidikan Islam sepakat bahwa tujuan pendidikan Islam adalah menciptakan pribadi-pribadi yang beriman dan taat beribadah kepada Allah SWT dalam arti yang seluas-luasnya.

2. Keimanan kepada Allah SWT berfungsi mendorong upaya peningkatan dibidang pengembangan ilmu pengetahuan. Hal ini dapat dipahami dari keharusan orang-orang yang beriman agar memperkuat keimanannya dengan dalil-dalil, baik yang bersifat naqli (AlQur'andan Hadis) maupun dalil- dalil yang bersifat aqli (yang dibangun dari argumentasi rasional). Keimanan kepada Allah tidak boleh didasarkan kepada ikutikutan atau taqlid. Karena keimanan yang seperti itulah yang akan menimbulkan sikap tanggung jawab, kreatif, dinamis, dan inovatif.

Sikap yang demikian muncul sebagai hasil dari proses internalisasi sifat-sifat Allah dalam diri manusia dan manifestasinya dalam kenyataan hidup sesuai kadar keanggupannya. Di dalam surat alMujadalah (59):11, Allah menjanjikan akan mengangkat derajat seseorang yang memiliki keimanan yang diperkuat oleh ilmu pengetahuan. Nurcholis Madjid, menyatakan bahwa iman mendidik kita untuk mempunyai komitmen kepada nilai-nilai luhur, dan ilmu memberikan kecakapan teknis guna merealisasikannya. Jadi iman dan ilmu secara bersanma akan membuat kita menjadi orang yang baik sekaligus tahu cara untuk mewujudkan kebaikan kita. Maka dengan demikian, dapat dimengerti bahwa iman dan ilmu merupakan jaminan keunggulan dan superioritas. ${ }^{9}$

3. Orang yang bertanggung jawab dalam menanamkan keimanan ini dalam diri anak adalah orang tua. Orang tua harus punya perhatian yang penuh terhadap pendidikan keimanan anaknya. Adapun cara yang harus ditempuh oleh orang tua agar keimanan itu tertancap dikalbu anak adalah diantaranya dengan mengazankan dan

\footnotetext{
${ }^{9}$ Nurcholis Madjid,Pintu-pintu Menuju Tuhan, (Jakarta : Paramadina, 1995), h.8
} 
mengiqamatkan anak ketika baru dilahirkan.

4. Memberi nama yang baik, serta memberi makan dengan makanan yang halal lagi baik. Disamping itu, orang tua selaku pendidik harus memiliki keimanan yang mantap dan kokoh terlebih dahulu.

5. Adapun metode yang biasa digunakan dalam pendidikan keimanan itu adalah metode nasehat, dialog, atau tanya jawab, serta metode perenungan (observasi), membaca tanda-tanda kekuasaan Allah.

Tetapi jadilah kalian orangorang yang mengesakan-Nya, mengikhlaskan diri hanya kepadaNya dalam beribadah, dan tiada yang kalian kehendaki dalam ibadah itu selain hanya karena-Nya.

Ibnu Jarir mengatakan, telah menceritakan kepadaku Yahya ibnu Wadih, telah menceritakan kepada kami Yunus ibnu Ishaq, dari Zaid ibnu Abu Maryam yang mengatakan bahwa Umar r.a. bersua dengan Mu'az ibnu Jabal, lalu Umar bertanya, "Apakah yang menjaga keutuhan tegaknya umat ini?" Mu'az menjawab, "Ada tiga perkara yang semuanya dapat menyelamatkan mereka, yaitu tetap pada fitrah Allah yang telah menciptakan manusia menurut fitrah itu; salat yang merupakan agama; dan taat yang merupakan pemelihara diri (dari perbuatan yang diharamkan)." Maka Umar berkata, "Engkau benar."

\section{Kesimpulan}

1. Pendapat sebagian ulama mengatakan bahwa hakikat iman itu tidak hanya tashdiq dengan hati saja, tapi berstruktur (murakkab), yaitu tersusun dari tashdiq dengan hati dan iqrar dengan lisan. Kemudian a'mal dengan arkan (anggota tubuh). Pendapat ini berkonsekuensi tidak beriman seseorang secara zahir dan batin bila ia hanya membenarkan dengan hati, tetapi tidak diikrarkan dengan lidahnya, padahal ia kuasa melaksanakannya. Akibatnya dia akan menjadi penghuni neraka karena belum dianggap beriman.serta mengaplikasikannya dengan perbuatan.

2. Sedangkan iman secara istilah adalah pengakuan dengan hati, pengucapan dengan lidah, dan pengamalan dengan anggota badan.

3. Uraian mengenai keimanan kepada Allah SWT dan pendidikan keimanan sebagaimana dapat dipahami dari kandungan ayat-ayat diatas memiliki hubungan yang erat dengan pendidikan Islam. Hal ini dapat dijelaskan sebagai berikut:

a. Keimanan kepada Allah SWT dengan segala uraian yang berkaitan dengannya, selain menjadi materi utama pendidikan Islam, juga dapat menjadi dasar bagi perumusan tujuan pendidikan, dasar penyusunan kurikulum dan aspek-aspek pendidikan lainnya.

b. Keimanan kepada Allah SWT berfungsi mendorong upaya peningkatan dibidang pengembangan ilmu pengetahuan.

c. Orang yang bertanggung jawab dalam menanamkan keimanan ini dalam diri anak adalah orang tua.

4. Adapun metode yang biasa digunakan dalam pendidikan keimanan itu adalah metode 
nasehat, dialog, atau Tanya jawab, serta metode perenungan (observasi), membaca tanda-tanda kekuasaan Allah.

\section{Daftar Kepustakaan}

Al-Qur'an al-Karim

Ahmad Mustafa al-Maraghi, Tafsir alMaraghi, Mesir: Mustafa Bab al-Halabi, t.th

Arief, Armai, Reformulasi Pendidikan Islam, (Jakarta: Crsd Press, 2005), Cet. I

Hamka, Tafsir Al-Azhar, Jakarta :

Pustaka Panji Mas, 1999

Madjid, Nurcholis, Pintu-pintu Menuju Tuhan, Jakarta, Paramadina, 1995

Quthb, Said., Fi Zhilal AlQur'an, ( Kairo: Dar al-Syuruq, 1981), Jilid 5

Al-Razi, Tafsir al-Kabir, juz 25, h.146.Baca : Abdullah al-
Ghamidi, Cara Mengajar (Anak/Murid) Ala Lukman alHakim (terj), (Yogyakarta : Sabil, 2011)

Ramayulis, Ilmu Pendidikan Islam, (Jakarta: Kalam Mulia, 2002)

Satiadarma, Monti P. Persepsi Orang Tua Membentuk Perilaku Anak: Dampak Pigmalion dalam Keluarga, ( Jakarta: Pustaka Populer Obor, 200

Tafsir, Ahmad., Metodologi Pengajaran Agama Islam, (Bandung: PT. Remaja Rosdakarya, 2007), Cet. IX, h. 6

Tim Penyusun Kamus Pusat Pembinaan dan Pengembangan Bahasa Departemen Pendidikan dan Kebudayaan, Kamus Besar Bahasa Indonesia, (Jakarta: Balai Pustaka, 2007), Cet. III 